\title{
A RESERVA LEGAL NO ÂMBITO DO CADASTRO AMBIENTAL RURAL: BREVE ANÁLISE DO SISTEMA DE REGULARIZAÇÃO AMBIENTAL DO IMÓVEL RURAL
}

\author{
Athila Leandro de Oliveira ${ }^{1}$ Luis Antônio Coimbra Borges ${ }^{2 *}$, Dalmo Arantes de Barros ${ }^{2}$, Sarita Soraia de \\ Alcântara Laudares², Thais Muniz Ottoni Santiago ${ }^{2}$, José Edimar Vieira Costa Júnior², \\ ${ }^{1}$ Universidade Federal Rural do Rio de Janeiro, Programa de Pós Graduação em Ciências Ambientais e Florestais, Departamento de \\ Conservação Ambiental, Seropédica, Rio de Janeiro, Brasil - athila_mg@ hotmail.com \\ 2* Universidade Federal de Lavras, Programa de Pós-Graduação em Engenharia Florestal, Lavras, Minas Gerais, Brasil - \\ luis.borges@dcf.ufla.br*; dalmo.barros@uol.com.br; saritalaudares@gmail.com; thaismottoni@gmail.com; jevcjunior@gmail.com.
}

Recebido para publicação: 01/11/2016 - Aceito para publicação: 14/12/2017

\begin{abstract}
Resumo
A Nova Lei Florestal ( $\mathrm{n}^{\circ}$ 12.651/2012), também conhecida como "Novo Código Florestal", trouxe, em seu artigo 68, a possibilidade dos proprietários ou possuidores de imóveis rurais, que realizaram supressão de vegetação nativa de acordo com os percentuais de Reserva Legal (RL) previstos nas legislações da época em que ocorreu a supressão, sejam dispensados de promover a recomposição. A ocupação consolidada das RL pode ser comprovada por todos os meios de prova em direito admitidos. Ao descrever as principais modificações normativas ao longo do tempo, a partir de uma revisão do arcabouço legal no tocante da RL, objetivou-se caracterizar as respectivas implicações ambientais da aplicação do artigo 68 da Nova Lei Florestal. Observou-se que a RL é um dispositivo que foi criado pelo $1^{\circ}$ Código Florestal de 1934 e passou por diversas transformações, a fim de torná-la mais efetiva na proteção do meio ambiente. O tipo de uso também foi sendo restringido. Entende-se que as legislações foram importantes para correções dos lapsos legais, uma vez que o $2^{\circ}$ Código Florestal, Lei $n^{\circ} 4.771 / 1965$, possibilitava interpretações dúbias, que foram posteriormente corrigidas. Conclui-se que o art. 68 consagra o direito adquirido, porém abre espaço para que aqueles que promoveram cortes rasos de forma legal deem continuidade ao ato que hoje é considerado ilícito. Por um lado, esta flexibilização trouxe prejuízos para a conservação das áreas de RL; por outro lado, permitiu ocupações de baixo impacto pelos agricultores familiares.

Palavras-chave: Legislação florestal, política florestal, recuperação ambiental.
\end{abstract}

\begin{abstract}
The Legal Reserve in the context of the Rural Environmental Registry: brief analysis of the environmental regularization system of rural property. The New Forest Law (Law $\mathrm{n}^{\circ} .12,651 / 2012$ ), also known as "New Forest Code", brought, in its Article 68, the possibility of owners of rural properties, who made the suppression of native vegetation according to the percentage of the Legal Reserve (RL) provided by the legislation of the time when suppression occurred, to be dispensed from promoting recovery. The consolidated load of RL can be proved by all evidences admitted. By describing the main legislative changes over time from a review of the legal framework, this paper aimed to characterize the respective environmental implications in the theoretical application of the Article 68 of the New Forest Law. In this study, we observed that the LR is a tool created by the 1st Forest Code from 1934, which passed through constant changes in order to make it more effective on the protection of the environment. The type of use was also restricted. We understand that such legislations were also important for fixing legal lapses, since the 2nd Forest Code from 1965 enabled dubious interpretations, which were fixed later. We conclude that the art. 68 establishes an acquired right; however, it enables those who promoted shallow cuts legally to continue this activity, which is considered an illegal act today. On one hand, this flexibility brought losses for the conservation of RL areas, on the other hand, it allowed occupation by familiar farmers.
\end{abstract}

Keywords: Forest legislation, forest policy, environmental recovery.

\section{INTRODUÇÃO}

A legislação brasileira tem sido de fundamental importância para a redução da degradação ambiental, uma vez que envolve os atores sociais em diversas ações relativas à restauração de ecossistemas degradados. Isso coloca o Brasil em posição pioneira entre os países que almejam harmonizar a produção econômica, o crescimento e a conservação da biodiversidade (CALMOM et al., 2011). No intuito de permitir que a exploração econômica das terras ocorra de modo a garantir a manutenção de um montante mínimo de serviços ambientais, os proprietários

FLORESTA, Curitiba, PR, v. 48, n. 1, p. 27-36, jan. /mar. 2018.

Oliveira. A.L. et al.

ISSN eletrônico 1982-4688

DOI: $10.5380 /$ rf.v48 i1.49110 
rurais têm sido obrigados a preservar áreas naturais em seus domínios, quer sejam: as Áreas de Preservação Permanentes (APPs) ou a chamada Reserva Legal (RL).

A RL compreende o percentual de área da propriedade rural (cujo valor varia a depender da região e do bioma em que o imóvel rural está inserido) em que a vegetação nativa deve ser mantida, permitindo-se exploração econômica apenas mediante ao manejo sustentável (SILVA; RANIERI, 2014).

Reforçando a preocupação com áreas de RL, determinou-se, também, a vedação de qualquer utilização que comprometa a integridade de suas características. Em casos de descumprimento da Lei, é possível incorrer em graves penalidades, que podem ser pela consumação de infrações administrativas (descritas no Decreto ${ }^{\circ}$ 6.514/2008) ou pela prática de crime ambiental (descritas na Lei $\mathrm{n}^{\circ}$ 9.605/1998) (FONSECA, 2014).

Devido à dificuldade de se cumprir a legislação, várias discussões se deram acerca da reformulação do Código Florestal de 1965 até a aprovação da Nova Lei Florestal n 12.651/2012 (BRASIL, 2012). Por meio desta Lei, reconheceu-se o passivo ambiental, que seria em torno de 50 milhões de hectares segundo estimativas em relação ao antigo Código Florestal, e trouxe o Programa de Regularização Ambiental (PRA). A partir deste programa, foi estabelecido um prazo para que aqueles que estivessem irregulares pudessem se adequar. Foi prevista a recuperação de aproximadamente 20 milhões de hectares, incluindo RL e APPs ripárias (SOARESFILHO et al., 2014).

Além disso, em seu art. 68, decretou que aqueles "que realizaram supressão de vegetação nativa respeitando os percentuais de Reserva Legal previstos pela legislação em vigor à época em que ocorreu a supressão são dispensados de promover a recomposição" (BRASIL, 2012). Com isso, reconheceu as diversas normativas anteriores no tocante ao dispositivo da RL. Assim, os proprietários ou posseiros rurais que possuem áreas de cobertura vegetal nativa menor que o exigido pela atual Lei Florestal não precisarão recompor, regenerar ou compensar sua RL, desde que comprovem que o que possuem de cobertura vegetal nativa estava em conformidade com alguma das legislações anteriores que regulamentavam a RL (BRASIL, 2012).

Este trabalho objetivou contextualizar as transformações pelas quais o instituto da RL passou até a atual Lei Florestal n ${ }^{\circ}$ 12.651/2012, visando elucidar as implicações de seu art. 68 em relação ao meio ambiente e aos proprietários e posseiros de imóveis rurais.

\section{MATERIAL E MÉTODOS}

Para este trabalho, foi realizada uma pesquisa documental por meio de consulta de Leis, Decretos e Portarias desde o $1^{\circ}$ Código Florestal, considerando o princípio do tratamento normativo sobre Reserva Legal. A pesquisa documental é diferenciada da pesquisa bibliográfica por recorrer a materiais que ainda não receberam tratamento analítico, ou seja, as fontes primárias (OLIVEIRA, 2007).

Também, utilizou-se pesquisa bibliográfica, que tem por finalidade tornar um assunto mais explícito (GIL, 2010). Dessa forma, foram analisadas as publicações acadêmicas que tratam da temática reserva legal em âmbito federal a fim de referenciar as principais críticas.

A partir da pesquisa documental, as normativas sobre o tema RL foram organizadas em uma tabela em ordem temporal crescente desde a $1^{\text {a }}$ normativa, o Código Florestal de 1934, Decreto lei ${ }^{\circ}$ 23.793/1934, até a atual, Lei $\mathrm{n}^{\circ} 12.651 / 2012$. Foram agrupadas as normativas consecutivas que não tiveram alterações no teor de porcentagem de proteção sobre os biomas nela considerados. As normativas foram agrupadas em 13 períodos. A organização foi necessária para melhor embasar as discussões sobre o enquadramento dos imóveis rurais na flexibilização prevista no artigo 68 da atual Lei Florestal e descrever as possíveis consequências para o meio ambiente e para os proprietários e posseiros de imóveis rurais.

\section{RESULTADOS}

A Tabela 1 mostra como o arcabouço legal relacionado à Reserva Legal evoluiu, desde a primeira legislação, que trouxe a obrigação de se respeitar uma área do imóvel com tal função. Também, é descrito se houve tratamento diferenciado do instrumento por região e se exigiu percentuais diferentes em relação ao tipo de fitofisionomia vegetal. Cada período é marcado por uma mudança na legislação e por novas regras, que são explicadas na coluna "outras considerações".

Tabela 1. Comparativo da evolução conceitual da Reserva Legal e suas respectivas implicações socioambientais. Table 1. Comparison on the conceptual evolution of the Legal Reserve and its respective socioenvironmental implications. 


\begin{tabular}{|c|c|c|c|c|c|c|}
\hline \multirow{2}{*}{$\begin{array}{l}\text { Período } \\
\text { de } \\
\text { vigência }\end{array}$} & \multirow[b]{2}{*}{$\begin{array}{c}\text { Instrumento } \\
\text { Legal }\end{array}$} & \multirow[b]{2}{*}{ Região } & \multicolumn{3}{|c|}{ Fitofisionomias florestais } & \multirow[t]{2}{*}{ Outras considerações } \\
\hline & & & Floresta & Cerrado & $\begin{array}{c}\text { Campos } \\
\text { Gerais }\end{array}$ & \\
\hline \multirow{2}{*}{$\begin{array}{l}\text { Anterior } \\
\text { à } \\
23 / 01 / 19 \\
34\end{array}$} & \multirow[b]{2}{*}{--- } & --- & --- & --- & --- & \multirow[b]{2}{*}{--- } \\
\hline & & --- & --- & --- & --- & \\
\hline $\begin{array}{c}23 / 01 / 19 \\
34 \text { à } \\
14 / 09 / 19 \\
65\end{array}$ & $\begin{array}{c}\text { Decreto Lei } \\
n^{\circ} 23.793, \text { de } \\
23 / 01 / 1934\end{array}$ & Qualquer região. & $25 \%$ & --- & --- & $\begin{array}{l}\text { Considera-se que este } \\
\text { dispositivo legal instituiu a } \\
\text { Reserva Legal ao impor um } \\
\text { limite ao uso da terra, para o } \\
\text { qual não seria permitido o } \\
\text { corte raso, em propriedades } \\
\text { privadas. Estabeleceu um } \\
\text { limite único para todo país. }\end{array}$ \\
\hline \multirow[b]{2}{*}{$\begin{array}{c}15 / 09 / 19 \\
65 \text { à } \\
17 / 07 / 19 \\
89\end{array}$} & \multirow[b]{2}{*}{$\begin{array}{c}\text { Lei } n^{\circ} 4.771, \\
\text { de } \\
15 / 09 / 1965 .\end{array}$} & $\begin{array}{l}\text { Região Norte e na } \\
\text { parte norte da } \\
\text { região Centro- } \\
\text { Oeste. }\end{array}$ & $50 \%$ & --- & --- & \multirow{2}{*}{$\begin{array}{c}\text { A Lei no } 4.771 / 1965 \text { impôs } \\
\text { novos limites para uso da terra } \\
\text { e exploração de florestas em } \\
\text { domínio privado com critérios } \\
\text { de acordo com a região e as } \\
\text { tipologias florestais. Deve-se } \\
\text { considerar que os Estados do } \\
\text { Mato Grosso e Goiás ainda não } \\
\text { tinham sido divididos formando } \\
\text { o Mato Grosso do Sul e } \\
\text { Tocantins. }\end{array}$} \\
\hline & & $\begin{array}{c}\text { Regiões Sudeste, } \\
\text { Sul e na parte sul } \\
\text { da região Centro- } \\
\text { Oeste. }\end{array}$ & $\begin{array}{l}20 \% \text { (regra geral); } \\
30 \% \text { (áreas ainda } \\
\text { não ocupadas ou } \\
\text { região Sul com } \\
\text { Araucaria } \\
\text { angustifolia). }\end{array}$ & --- & --- & \\
\hline \multirow[b]{2}{*}{$\begin{array}{l}18 / 07 / 19 \\
89 \text { à } \\
18 / 10 / 19 \\
94\end{array}$} & \multirow[b]{2}{*}{$\begin{array}{c}\text { Lei } n^{\circ} 7.803 \\
\text { de } \\
18 / 07 / 1989 .\end{array}$} & $\begin{array}{l}\text { Região Norte e na } \\
\text { parte norte da } \\
\text { região Centro- } \\
\text { Oeste. }\end{array}$ & $50 \%$ & $20 \%$ & --- & \multirow{2}{*}{$\begin{array}{c}\text { A Lei no 7.803/1989 iniciou o } \\
\text { uso da denominação Reserva } \\
\text { Legal. Nela, os critérios da Lei } \\
\mathrm{n}^{\circ} 4.771 / 1965 \text { foram mantidos. } \\
\text { Também, passou-se a exigir } \\
\text { 20\% para áreas recobertas por } \\
\text { cerrado. Portanto, a partir de } \\
\text { então, não esteve mais restrita } \\
\text { à cobertura florestal. A partir } \\
\text { desta lei, também foi instituída } \\
\text { a obrigatoriedade da averbação } \\
\text { junto à matrícula do imóvel. }\end{array}$} \\
\hline & & $\begin{array}{c}\text { Regiões Sudeste, } \\
\text { Sul e na parte sul } \\
\text { da região Centro- } \\
\text { Oeste. }\end{array}$ & $\begin{array}{l}20 \% \text { (regra geral); } \\
30 \% \text { (áreas ainda } \\
\text { não ocupadas ou } \\
\text { região Sul com } A . \\
\text { angustifolia). }\end{array}$ & $20 \%$ & --- & \\
\hline \multirow{2}{*}{$\begin{array}{l}19 / 10 / 19 \\
94 \text { à } \\
24 / 07 / 19 \\
96\end{array}$} & \multirow{2}{*}{$\begin{array}{c}\text { Decreto } \mathrm{n}^{\circ} \\
1.282, \mathrm{de} \\
19 / 10 / 1994 .\end{array}$} & $\begin{array}{l}\text { Região Norte e na } \\
\text { parte norte da } \\
\text { região Centro- } \\
\text { Oeste }\end{array}$ & $50 \%$ & $20 \%$ & --- & \multirow{2}{*}{$\begin{array}{c}\text { O Decreto } \mathrm{n}^{\circ} 1.282 / 1994 \\
\text { regulamentou o art. } 19 \text { da Lei } \\
\mathrm{n}^{\circ} 4.771 / 1965, \text { que dava } \\
\text { detalhes sobre o uso da } \\
\text { Reserva Legal. Este Decreto } \\
\text { determinou procedimentos } \\
\text { para concessão de autorização } \\
\text { de corte raso para conversão } \\
\text { de áreas para uso alternativo } \\
\text { do solo e o uso do ZEE para a } \\
\text { fixação de percentuais de } \\
\text { acréscimo da Reserva Legal na } \\
\text { bacia amazônica. }\end{array}$} \\
\hline & & $\begin{array}{l}\text { Regiões Sudeste, } \\
\text { Sul e na parte sul } \\
\text { da região Centro- } \\
\text { Oeste. }\end{array}$ & $\begin{array}{c}20 \% \text { (regra geral); } \\
30 \% \text { (áreas ainda } \\
\text { não ocupadas ou } \\
\text { região Sul com } A . \\
\text { angustifolia). }\end{array}$ & $20 \%$ & --- & \\
\hline
\end{tabular}

FLORESTA, Curitiba, PR, v. 48, n. 1, p. 27-36, jan. /mar. 2018.

Oliveira. A.L. et al.

ISSN eletrônico 1982-4688

DOI: $10.5380 /$ rf.v48 i1.49110 
... Continuação Tabela 1.

\begin{tabular}{|c|c|c|c|c|c|c|}
\hline \multirow{2}{*}{$\begin{array}{c}\text { Período de } \\
\text { vigência }\end{array}$} & \multirow[b]{2}{*}{$\begin{array}{c}\text { Instrumento } \\
\text { Legal }\end{array}$} & \multirow[b]{2}{*}{ Região } & \multicolumn{3}{|c|}{ Fitofisionomias florestais } & \multirow[b]{2}{*}{ Outras considerações } \\
\hline & & & Floresta & Cerrado & $\begin{array}{c}\text { Campos } \\
\text { Gerais }\end{array}$ & \\
\hline \multirow[t]{2}{*}{$\begin{array}{l}25 / 07 / 19 \\
96 \text { à } \\
26 / 06 / 19 \\
97\end{array}$} & \multirow[t]{2}{*}{$\begin{array}{c}\mathrm{MP} \mathrm{n}^{\circ} 1.511- \\
1 / 11, \mathrm{de} \\
25 / 07 / 1996 .\end{array}$} & $\begin{array}{c}\text { Estados do AC, } \\
\text { PA, AM, RR, RO, } \\
\text { AP e MT, além } \\
\text { das regiões } \\
\text { situadas ao norte } \\
\text { do paralelo } 13^{\circ} \mathrm{S}, \\
\text { TO e GO, e a } \\
\text { oeste do } \\
\text { meridiano de } \\
44^{\circ} \mathrm{W}, \text { no Estado } \\
\text { do MA. }\end{array}$ & $80 \%$ & $50 \%$ & --- & \multirow{2}{*}{$\begin{array}{c}\text { A MP manteve os critérios } \\
\text { anteriores contidos na Lei } \mathrm{n}^{\circ} \\
4.771 / 1965 \text { e procedimentos } \\
\text { de regulamentos } \\
\text { estabelecidos } \\
\text { posteriormente. Especificou } \\
\text { quais Estados são } \\
\text { pertencentes às regiões } \\
\text { Norte e parte norte da região } \\
\text { Centro-Oeste. Além disso, } \\
\text { aumentou o percentual de } \\
\text { RL em áreas de floresta para } \\
\text { 80\% e para outras coberturas } \\
\text { arbóreas, } 50 \% \text {. }\end{array}$} \\
\hline & & Demais regiões. & $\begin{array}{l}20 \% \text { (regra geral); } \\
30 \% \text { (áreas ainda } \\
\text { não ocupadas ou } \\
\text { região Sul com } A . \\
\text { angustifolia). }\end{array}$ & $20 \%$ & --- & \\
\hline \multirow[t]{2}{*}{$\begin{array}{c}27 / 06 / 1997 \\
a \\
10 / 12 / 1997\end{array}$} & \multirow[t]{2}{*}{$\begin{array}{c}\mathrm{MP} \mathrm{n}^{\circ} 1.511- \\
12 / 17, \mathrm{de} \\
27 / 06 / 1997\end{array}$} & $\begin{array}{c}\text { Estados do AC, } \\
\text { PA, AM, RR, RO, } \\
\text { AP e MT, além } \\
\text { das regiões } \\
\text { situadas ao norte } \\
\text { do paralelo } 13^{\circ} \mathrm{S}, \\
\text { TO e GO, e a } \\
\text { oeste do } \\
\text { meridiano de } \\
44^{\circ} \mathrm{W}, \text { no Estado } \\
\text { do MA. }\end{array}$ & $80 \%$ & $50 \%$ & --- & \multirow[t]{2}{*}{$\begin{array}{c}\text { Merece atenção especial } \\
\text { em relação às MPs da série } \\
\mathrm{n}^{\circ} 1.511 \text { por possibilitar a } \\
\text { redução do limite da RL de } \\
80 \% \text { para } 50 \% \text { em imóveis } \\
\text { rurais abaixo de } 100 \text { ha, } \\
\text { nos quais houvesse a } \\
\text { prática de agropecuária } \\
\text { familiar. }\end{array}$} \\
\hline & & Demais regiões. & $\begin{array}{l}20 \% \text { (regra geral); } \\
30 \% \text { (áreas ainda } \\
\text { não ocupadas ou } \\
\text { região Sul com } A . \\
\text { angustifolia). }\end{array}$ & $20 \%$ & --- & \\
\hline \multirow[t]{2}{*}{$\begin{array}{c}11 / 12 / 1997 \\
\text { à } \\
18 / 11 / 1998\end{array}$} & $\begin{array}{c}\text { MP no }^{\circ} 1.605- \\
18 / 29, \text { de } \\
11 / 12 / 1997\end{array}$ & $\begin{array}{c}\text { Estados do AC, } \\
\text { PA, AM, RR, RO, } \\
\text { AP e MT, além } \\
\text { das regiões } \\
\text { situadas ao norte } \\
\text { do paralelo } 13^{\circ} \mathrm{S}, \\
\text { TO e GO, e a } \\
\text { oeste do } \\
\text { meridiano de } \\
44^{\circ} \mathrm{W}, \text { no Estado } \\
\text { do MA. } \\
\end{array}$ & $80 \%$ & $50 \%$ & --- & \multirow{2}{*}{$\begin{array}{l}\text { A MP manteve os critérios } \\
\text { anteriores contidos na Lei } \\
\text { e incorporou os } \\
\text { procedimentos dos } \\
\text { regulamentos contidos nos } \\
\text { Decretos emitidos desde a } \\
\text { Lei } \mathrm{n}^{\circ} 4.771 / 1965 \text { e da MP } \\
\mathrm{n}^{\circ} 1.511 \text {, fortalecendo os } \\
\text { procedimentos de } \\
\text { ordenamento baseados no } \\
\text { ZEE. }\end{array}$} \\
\hline & & Demais regiões. & $\begin{array}{l}20 \% \text { (regra geral); } \\
30 \% \text { (áreas ainda } \\
\text { não ocupadas ou } \\
\text { região Sul com } A . \\
\text { angustifolia). }\end{array}$ & $20 \%$ & --- & \\
\hline
\end{tabular}


... Continuação Tabela 1.

\begin{tabular}{|c|c|c|c|c|c|c|}
\hline \multirow{2}{*}{$\begin{array}{l}\text { Período de } \\
\text { vigência }\end{array}$} & \multirow{2}{*}{$\begin{array}{c}\text { Instrumento } \\
\text { Legal }\end{array}$} & \multirow[b]{2}{*}{ Região } & \multicolumn{3}{|c|}{ Fitofisionomias florestais } & \multirow[b]{2}{*}{ Outras considerações } \\
\hline & & & Floresta & Cerrado & $\begin{array}{c}\text { Campos } \\
\text { Gerais }\end{array}$ & \\
\hline \multirow[t]{2}{*}{$\begin{array}{c}19 / 11 / 1998 \\
\text { à } \\
13 / 12 / 1998\end{array}$} & \multirow[t]{2}{*}{$\begin{array}{c}\mathrm{MP} \mathrm{n}^{\circ} 1.605- \\
30, \text { de } \\
19 / 11 / 1998 .\end{array}$} & $\begin{array}{c}\text { Estados do AC, } \\
\text { PA, AM, RR, RO, } \\
\text { AP e MT, além } \\
\text { das regiões } \\
\text { situadas ao norte } \\
\text { do paralelo } 13^{\circ} \mathrm{S}, \\
\text { TO e GO, e a } \\
\text { oeste do } \\
\text { meridiano de } \\
44^{\circ} \mathrm{W}, \text { no Estado } \\
\text { do MA. }\end{array}$ & $80 \%$ & $50 \%$ & --- & \multirow{2}{*}{$\begin{array}{l}\text { A última MP da série } \mathrm{n}^{\circ} \\
1.605-18 / 30 \text { merece } \\
\text { destaque por oferecer aos } \\
\text { proprietários de imóveis } \\
\text { rurais da região Amazônica a } \\
\text { possibilidade de compensar } \\
\text { a RL em áreas de outras } \\
\text { propriedades, embora tenha } \\
\text { mantido os mesmos } \\
\text { percentuais de RL exigidos. }\end{array}$} \\
\hline & & Demais regiões. & $\begin{array}{l}20 \% \text { (regra geral); } \\
30 \% \text { (áreas ainda } \\
\text { não ocupadas ou } \\
\text { região Sul com } A . \\
\text { angustifolia). }\end{array}$ & $20 \%$ & --- & \\
\hline
\end{tabular}

\begin{tabular}{|c|c|c|c|c|c|}
\hline \multirow[t]{2}{*}{$\begin{array}{c}14 / 12 / 1998 \\
\text { à } \\
25 / 05 / 2000\end{array}$} & \multirow[t]{2}{*}{$\begin{array}{c}\mathrm{MP} \mathrm{n}^{\circ} 1.736- \\
31 / 37, \mathrm{de} \\
\text { 14/12/1998; } \\
\mathrm{MP} \mathrm{n}^{\circ} 1.885- \\
38 / 43, \mathrm{de} \\
\text { 29/06/1999; } \\
\mathrm{MP} \mathrm{n}^{\circ} 1.956- \\
44 / 50, \mathrm{de} \\
9 / 12 / 1999\end{array}$} & $\begin{array}{c}\text { Estados do AC, } \\
\text { PA, AM, RR, RO, } \\
\text { AP e MT, além } \\
\text { das regiões } \\
\text { situadas ao norte } \\
\text { do paralelo } 13^{\circ} \mathrm{S}, \\
\text { nos Estados de } \\
\text { TO e GO, e a } \\
\text { oeste do } \\
\text { meridiano de } \\
44^{\circ} \mathrm{W}, \text { no Estado } \\
\text { do MA. }\end{array}$ & $80 \%$ & $20 \%$ & --- \\
\hline & & Demais regiões. & $\begin{array}{l}20 \% \text { (regra geral); } \\
30 \% \text { (áreas ainda } \\
\text { não ocupadas ou } \\
\text { região Sul com } A . \\
\text { angustifolia). }\end{array}$ & $20 \%$ & -- \\
\hline
\end{tabular}

A MP manteve os critérios anteriores contidos na Lei $\mathrm{n}^{\circ}$ 4.771/1965 e incorporou os procedimentos dos regulamentos contidos nos Decretos e MPs posteriores. $O$ percentual de cerrado na região Amazônica foi reduzido para $20 \%$.

Destacam-se as 8 últimas MPs da série $\mathrm{n}^{\circ}$ 1956-44/57 por trazerem especificidades importantes: 1) pela primeira vez, a RL foi conceituada; 2)

Amazônia Legal. $\quad 80 \% \quad 35 \% \quad 20 \%$ importantes modificações quanto aos percentuais da RL ocorreram; $35 \%$ em cerrado da região Amazônica. Pela primeira vez, é tratada a RL em campos gerais; $20 \%$ para

\section{$26 / 05 / 2000$ \\ à $26 / 12 / 2000 \quad 51 / 57$, de \\ $26 / 05 / 2000$}

todo o país; 3) a MP inseriu restrições ao cômputo de acordo com a região e tipo de propriedade; 4) para aqueles que não tinham RL, passou a exigir-se

Demais regiões. $\quad 20 \% \quad 20 \% \quad 20 \%$
recomposição, condução ou compensação, salvo algumas exceções de acordo com o tipo de propriedade; 6) a MP instituiu a servidão florestal e a CRA; 7) a MP instituiu a possibilidade de estabelecer RL em condomínio. 
... Continuação Tabela 1

\begin{tabular}{|c|c|c|c|c|c|c|}
\hline \multirow{2}{*}{$\begin{array}{l}\text { Período de } \\
\text { vigência }\end{array}$} & \multirow{2}{*}{$\begin{array}{c}\text { Instrumento } \\
\text { Legal }\end{array}$} & \multirow[b]{2}{*}{ Região } & \multicolumn{3}{|c|}{ Fitofisionomias florestais } & \multirow[b]{2}{*}{ Outras considerações } \\
\hline & & & Floresta & Cerrado & $\begin{array}{c}\text { Campos } \\
\text { Gerais } \\
\end{array}$ & \\
\hline \multirow[b]{2}{*}{$\begin{array}{c}27 / 12 / 2000 \\
\text { à } \\
21 / 07 / 2008\end{array}$} & \multirow{2}{*}{$\begin{array}{c}\mathrm{MP} \mathrm{n}^{\circ} 2.080- \\
58 / 64, \text { de } \\
27 / 12 / 2000 \mathrm{e} \\
\mathrm{MP} \mathrm{n}^{\circ} 2.166- \\
65 / 67, \mathrm{de} \\
28 / 06 / 2001\end{array}$} & Amazônia Legal. & $80 \%$ & $35 \%$ & $20 \%$ & \multirow{2}{*}{$\begin{array}{c}\text { Não houve modificações } \\
\text { significativas dos critérios, } \\
\text { procedimentos e percentuais } \\
\text { firmados pela MP nº 1.956- } \\
50 / 1957 ; \text { como } \\
\text { compensação, CRA e } \\
\text { condomínio para RL. Vê-se } \\
\text { uma mudança no modelo de } \\
\text { gestão ao adotar uma gestão } \\
\text { compartilhada para políticas } \\
\text { ambientais ao definir o papel } \\
\text { dos Órgãos Estaduais de } \\
\text { Meio Ambiente na } \\
\text { localização, uso e } \\
\text { recomposição da RL no } \\
\text { imóvel rural. }\end{array}$} \\
\hline & & Demais regiões. & $20 \%$ & $20 \%$ & $20 \%$ & \\
\hline \multirow[b]{2}{*}{$\begin{array}{l}\text { A partir de } \\
22 / 07 / 2008\end{array}$} & \multirow[b]{2}{*}{$\begin{array}{c}\text { Lei n }{ }^{\circ} \\
12.651, \text { de } \\
25 / 05 / 2012 .\end{array}$} & Amazônia Legal. & $80 \%$ & $35 \%$ & $20 \%$ & \multirow{2}{*}{$\begin{array}{c}\text { Continuou a exigir os } \\
\text { mesmos percentuais } \\
\text { estabelecidos na MP n } \\
\text { 1.956-51/1957. Para garantir } \\
\text { a efetividade da } \\
\text { regularização dessas e de } \\
\text { outras áreas nos imóveis } \\
\text { rurais, diversos instrumentos } \\
\text { criados anteriormente foram } \\
\text { adaptados, como é o caso da } \\
\text { compensação, recomposição, } \\
\text { RL em condomínio, CRA, } \\
\text { entre outros. }\end{array}$} \\
\hline & & Demais regiões. & $20 \%$ & $20 \%$ & $20 \%$ & \\
\hline
\end{tabular}

\section{DISCUSSÃO}

\section{Entendendo o objeto de estudo: a Reserva Legal}

A ideia de reservar parte do imóvel para conservação de florestas tem referência nas iniciativas de José Bonifácio ainda em 1821, mas só ressurgiu em 1934, quando foi publicado o $1^{\circ}$ Código Florestal Brasileiro, Decreto $^{\circ}{ }^{23.793 / 1934}$ (SILVA, 1821). Este pretendia proteger 25\% da vegetação de todo imóvel rural. Por isso, foi considerado o primórdio do conceito de Reserva Legal, apesar de não trazer o termo no corpo da lei. Nesta área, devia-se manter a cobertura florestal, apesar de haver um regime diferente do atual uma vez que permitia a homogeneização desta área ao cortar a floresta nativa. Sendo assim, foi considerado como a primeira legislação a exigir a "Reserva Legal", ainda que essa exigência fosse restrita à fitofisionomia florestal, e não abrangesse biomas, como o cerrado, e formações vegetais, como a restinga.

Como destacado por Bacha (2004), durante todo o período em que esse $1^{\circ}$ Código esteve vigente, o país encontrava-se em um modelo de desenvolvimento que privilegiava as atividades industriais e urbanas. Esse modelo começou a mudar na década de 1960, quando houve uma transição para uma concepção mais conservacionista ao se tratar de bens ambientais. Isso levou à reformulação da Lei e à publicação do $2^{\circ}$ Código Florestal, Lei ${ }^{\circ}$ 4.771/1965, considerado um paradigma na Política Florestal em busca do uso sustentável do imóvel.

Nesse Código, foram definidos, de forma mais aplicada, os domínios fitogeográficos no território nacional. As Florestas de Preservação Permanente e as Reservas Florestais foram consideradas como bens de interesse comum a toda a população (BORGES et al., 2011). Essa ideia foi reforçada com o estabelecimento da Constituição Federal de 1988, devendo o poder público e a coletividade defendê-lo. 
Porém, ainda assim, muitos proprietários continuaram a desrespeitar a Lei. Parte deles discordava da aplicabilidade da norma, uma vez que esta relacionava remanescentes de vegetação nativa a áreas "florestais", o que poderia excluir as "formações campestres nativas" e áreas já antropizadas; fato que se tentou corrigir por meio de Leis como a $n^{\circ} 7.754 / 1989$ e n $n^{\circ} 7.803 / 1989$ posteriormente. Esta última obrigou, ainda, a averbação, isto é, um modo de se "cadastrar" a RL e ter mais controle sobre tal dispositivo.

Ao reconhecer que muitos imóveis não respeitavam as áreas de RL e que o instrumento apresentava falhas, no início de 1991, passou a ser exigida a recomposição da RL por meio da Lei no 8.171/1991. Essa Lei estabeleceu, em seu artigo 99, a obrigação da recomposição da Reserva Legal, que deveria ser realizada em até 30 anos (JUCÁ, 2007). Porém, essa recomposição dificilmente ocorria por iniciativa própria. Normalmente, ocorria somente quando o produtor era pressionado por forças do mercado ou por ordem judicial.

A Lei Florestal continuou a passar por alterações que objetivavam torná-la mais combativa ao desmatamento (KENGEM, 2001). Por meio de Medidas Provisórias (MPs), como a n $1.511 / 1996$, buscou-se conciliar produção e preservação, alterando as porcentagens de Reserva Legal exigidas. Contudo, devido ao grande número de edições, acabou deixando os proprietários de imóveis inseguros quanto ao tratamento do uso alternativo do solo em imóveis rurais (SANTIAGO, 2006). Porém, deve-se ressaltar que foram importantes por consolidar as Reservas Legais como "áreas" independentes de que ainda houvesse cobertura florestal, evitando conflitos e interpretações dúbias (BORGES et al., 2011).

A quem ainda insistisse em não cumprir a Lei, restava o cumprimento da Lei de Crimes Ambientais $\mathrm{n}^{\circ} 9.605 / 1998$, que tratava das sanções penais e atividades lesivas ao meio ambiente e abriu possibilidade para a aplicação de multas. A partir de então, aqueles que possuíam algum passivo ambiental deveriam regularizá-los ou estariam sujeitos a multa, o que poderia afetar os pequenos agricultores de forma mais agravada, visto que mesmo uma pequena área poderia ser de grande importância para eles (SOS FLORESTAS, 2011).

O desafio da Nova Lei Florestal $n^{\circ} 12.651 / 2012$ foi mais do que sintetizar todo o emaranhado de conceitos, obrigações e regulamentações que se encontravam dispersas no Código anterior em um mesmo documento. Esta Lei teve que trazer, de forma inédita, um instrumento pioneiro em âmbito nacional para registro de todos imóveis rurais, o Cadastro Ambiental Rural (CAR).

\section{O Cadastro Ambiental Rural e a regularização da Reserva Legal}

O CAR é um registro eletrônico obrigatório para todos os imóveis rurais. Suas informações são integradas por meio do Sistema de Cadastro Ambiental Rural (SICAR), uma plataforma disponível em um site específico pelo qual é possível fazer o cadastro, a consulta e o acompanhamento da situação de regularização ambiental dos imóveis rurais. Cadastrar o imóvel é apenas o primeiro passo para o Programa de Regularização Ambiental (PRA), forma pela qual é conhecido o conjunto de atividades a serem desenvolvidas e implementadas no imóvel rural com vista a atender ao disposto na legislação ambiental e garantir a manutenção e recuperação de APPs, Áreas de Uso Restrito e RLs (BRASIL, 2012).

O Cadastro Ambiental Rural não é um programa inédito no território brasileiro. A atual Lei Florestal apenas o trouxe a âmbito nacional. Os cadastros já eram realizados no norte do país, especialmente Mato Grosso e Pará, com objetivo de reconhecer o território, permitir uma fiscalização mais eficiente e evitar desmatamentos. Sendo assim, pode-se relacionar seus primórdios ao Sistema de Licenciamento Ambiental em Propriedades Rurais (SLAPR) a partir do Decreto Estadual n 1.401/97 (AZEVEDO et al., 2014).

A região norte saiu na frente nos cadastros, uma vez que alguns estados já vinham implementando políticas semelhantes. Em âmbito nacional, todos os imóveis rurais passaram ter obrigação de se cadastrar apenas a partir da Lei Federal n ${ }^{\circ}$ 12.651/2012; e o módulo para realização dos cadastros (a plataforma nacional) só entrou em funcionamento no dia 28 de setembro de 2013, mais de um ano após a publicação da Lei Florestal. Apesar de haver demora na disponibilização do módulo para os cadastros e dificuldades para realização dos cadastros devido à gama de produtores com diferentes níveis de instrução, as flexibilidades a quem os realizasse no prazo e as restrições de crédito a quem não os realizasse foram motivos suficientes para os cadastros de 4,5 milhões de imóveis rurais, que totalizaram uma área de mais de 418 milhões de hectares inseridos na base de dados do sistema (BRASIL, 2017).

Historicamente, as Leis Florestais tiveram pouco impacto sobre o uso da terra, mesmo com os ajustes conservacionistas que sofreram ao longo do tempo. Portanto, a adoção de um instrumento como o CAR é vista como uma importante inovação no auxílio à maior eficácia da fiscalização sobre as transformações do uso da terra (SANTIAGO, 2017), mesmo que tenha havido o custo de flexibilidades na regularização ambiental do imóvel, que podem incluir recuperação de faixas menores em Áreas de Preservação Permanente ou Reserva Legal, para o sucesso da etapa de cadastros.

FLORESTA, Curitiba, PR, v. 48, n. 1, p. 27-36, jan. /mar. 2018.

Oliveira. A.L. et al.

ISSN eletrônico 1982-4688

DOI: $10.5380 /$ rf.v48 i1.49110 


\section{Entendendo as implicações do art. 68 para a regularização de um imóvel rural}

Além de trazer novidades como o CAR e o Programa De Regularização Ambiental, a atual Lei Florestal reconheceu as mudanças legislativas anteriores sobre a proteção de áreas conhecidas como RL. O artigo 68 da Lei esclareceu que os proprietários ou possuidores de imóveis rurais, que realizaram supressão de vegetação nativa respeitando os percentuais previstos pela legislação em vigor à época em que ocorreu a supressão, são dispensados de promover a recomposição, compensação ou regeneração para os percentuais atualmente exigidos pela nova Lei Florestal. Para ter direito às flexibilidades trazidas pela Lei $\mathrm{n}^{\circ} 12.651 / 2012$, as situações consolidadas devem ser comprovadas por documentos, tais como a descrição de fatos históricos de ocupação da região, registros de comercialização, dados agropecuários da atividade, contratos e documentos bancários relativos à produção, ou quaisquer outros meios de prova usualmente admitidos judicialmente.

O cadastrante que quiser fazer uso da flexibilidade trazida pelo art. 68 deve continuar a obedecer o percentual de "Reserva Legal" de acordo com outra legislação em vigor à época em que realizou a supressão. Também, deve responder a uma questão no momento do Cadastro de seu imóvel rural no Módulo de Cadastro, disponibilizado no site <http://www.car.gov.br>: “A Reserva Legal do imóvel rural está submetida à legislação de que período?". Para responder a esta parte do questionário do Cadastro Ambiental Rural, o proprietário ou posseiro rural encontra disponível 11 períodos que correspondem a alterações sobre o dispositivo da RL. Dessa forma, um determinado imóvel que tenha, por exemplo, comprovantes de seu desmate legal realizado anteriormente a 1934 pode estar desobrigado da regularização para os percentuais atuais.

Esses períodos são marcados não somente por mudanças em termos de percentuais, mas, também, por possibilidades de uso e manejo da RL. Porém, não são detalhadas no Módulo de Cadastro, nem na atual Lei Florestal, quais foram as alterações ocorridas em cada período. Na Tabela 1, estas normativas foram organizadas em 13 períodos marcados por mudanças na caracterização da RL, seja pelo tipo de fitofisionomia que abrangiam, seja pela porcentagem exigida ou por outras considerações, que podem ser obrigações ao proprietário ou aos posseiro rural.

Pode-se observar, a partir da Tabela 1, que a legislação foi pontualmente alterada no tocante à RL com o passar dos anos, sendo corrigidas falhas e criando restrições. Contudo, com a atual Lei Florestal $n^{\circ}$ 12.651/2012, o dispositivo foi alterado para que aqueles que ainda não tinham o mínimo exigido pela Lei anterior $\mathrm{n}^{\circ} 4.771 / 1965$ pudessem se regularizar. A legislação trouxe maior flexibilidade, visando não só a conservação, mas também a manutenção da rentabilidade agrícola.

De acordo com o art. 68 da Lei n ${ }^{\circ} 12.651 / 2012$, é possível, por exemplo, que um imóvel situado em área de cerrado, que tenha sido desmatado anteriormente a 1989, não precise recuperar nenhuma área com intuito de compor sua RL, uma vez que, somente com a Lei $\mathrm{n}^{\circ}$ 7.803/1989, passou a ser exigida RL neste bioma. Além disso, quem desmatou antes de 1934 estaria totalmente isento de compor a RL nos atuais termos, uma vez que não era exigida antes do Decreto Lei ${ }^{\circ} 23.793 / 1934$.

Nunes (2014) estudou os principais anos que ocorreram mudanças nas leis ambientais sobre o dispositivo da Reserva Legal e os relacionou com a abertura de novas áreas agrícolas nas diversas regiões do país de forma a tentar entender como o art. 68 pode influenciar sobre o passivo da RL. Observou que, com o disposto desse artigo, áreas com maior uso agropecuário tem menor obrigação de recompor. Além disso, constatou que, embora a temporalidade tenha potencial de atuar em todas as regiões do país, a região Norte é a que tem menor capacidade relativa de seu uso, exatamente por ser a menos explorada historicamente.

A Tabela 1 mostra 13 períodos nos quais os produtores rurais podem caracterizar seu imóvel, 2 períodos a mais do que o Módulo de Cadastro do SICAR. Estes foram destacados pela MP n 1.511/1996, que permitiu a redução da área de RL de $80 \%$ para $50 \%$ em imóveis rurais abaixo de 100 ha a partir de sua $12^{\mathrm{a}}$ edição. Além disso, a MP n ${ }^{\circ} 1.956 / 2000$, na $51^{\text {a }}$ edição, foi a primeira a trazer a exigência de RL em campos gerais, ambientes que, até então, eram muito discutidos pela necessidade de proteção, mas ainda estavam fragilizados legalmente.

Sugerem-se, a partir desta revisão, alterações no sistema no qual são realizados os cadastros. No entanto, deve-se destacar que estas ferramentas dependem de apontamentos por dirigentes dos órgãos públicos a elas relacionados. Também, é importante a cobrança de alterações a partir de estudos acadêmicos, de forma que as tornem mais condizente com a realidade. 


\section{CONCLUSÃO}

- A atual Lei Florestal, em seu artigo 68, consagra o direito adquirido e permite que aqueles que já regularizaram a RL de seus imóveis com base em legislações anteriores não tenham que refazê-la segundo a atual legislação. Porém, para isso, os proprietários precisam conhecer ou ter apoio técnico sobre os períodos das intervenções para o enquadramento de seu imóvel.

- A flexibilização da lei abre espaço para que aqueles que promoveram cortes rasos de forma legal possam dar continuidade a este ato que é hoje considerado ilícito, uma vez que não estão promovendo a proteção ambiental em seus imóveis, um direito de todos garantidos pela Constituição Federal. Essa flexibilização traz prejuízos para a conservação das áreas de RL.

\section{AGRADECIMENTOS}

À FAPEMIG, CNPq e a CAPES pelo apoio. Ao NEPPA, Núcleo de Estudos em Pesquisa e Planejamento Ambiental, e aos colegas que direta ou indiretamente contribuíram para a concretização deste trabalho.

\section{REFERÊNCIAS}

AZEVEDO, A.; RAJÃO, R. G. L.; COSTA, M.; STABILE, M. C. C. Cadastro Ambiental Rural e sua influência na dinâmica do desmatamento na Amazônia Legal. Brasília: IPAM, 2014. Disponível em: $<$ http://ipam.org.br/bibliotecas/amazonia-em-pauta-3-cadastro-ambiental-rural-e-sua-influencia-na-dinamica-dodesmatamento-na-amazonia-legal/>. Acesso em: 17/11/2017.

BACHA, C. J. C. O Uso de recursos florestais e as políticas econômicas brasileiras: uma visão histórica e parcial de um processo de desenvolvimento. Estudos Econômicos. vol.34, n.2, p. 393-426, 2004. Disponível em: <http://www.scielo.br/scielo.php?pid=S0101-41612004000200007\&script=sci_arttext $>$. Acesso em: 20/11/2015.

BORGES, L. A. C., REZENDE, J. L. P., PEREIRA, J. A. A., COELHO JÚNIOR, L. M., BARROS, D. A. Áreas de preservação permanente na legislação ambiental brasileira. Cienc. Rural, Santa Maria, v. 41, n. 7, p. 12021210, Julho de 2011. Disponível em: <http://www.scielo.br/scielo.php?script=sci_arttext\&pid=S010384782011000700016\&lng=en\&nrm=iso>. Acesso em: 24/04/2015. <http://dx.doi.org/10.1590/S010384782011000700016>.

BRASIL. Lei 12.651, de 25 de maio de 2012. Dispõe sobre a proteção da vegetação nativa; altera as Leis $n^{\circ} 6.938$, de 31 de agosto de 1981, 9.393, de 19 de dezembro de 1996, e 11.428, de 22 de dezembro de 2006; revoga as Leis $\mathrm{n}^{\circ}$ 4.771, de 15 de setembro de 1965, e 7.754, de 14 de abril de 1989, e a Medida Provisória no 2.166-67, de 24 de agosto de 2001; e dá outras providências. Diário Oficial da União: República Federativa do Brasil, Brasília, DF, 28 maio 2012. Disponível em: 〈http://www.planalto.gov.br/ccivil_03/_ato2011-2014/2012/lei/112651.htm〉. Acesso em: 28/06/2015.

BRASIL. Serviço Florestal Brasileiro (SFB). CAR: boletim informativo (2017). Disponível: http://www.florestal.gov.br/index.php?option=com_content\&view=article\&id=77:numeros-do-cadastroambiental-rural\&catid=61. Acesso em: 17/11/2017.

CALMON, M., BRANCALION, P. H., PAESE, A., ARONSON, J., CASTRO, P., SILVA, S. C., RODRIGUES, R. R. Emerging Threats and Opportunities for Large-Scale Ecological Restoration in the Atlantic Forest of Brazil. Restoration Ecology, 19(2), 154-158. 2011. Disponível em: <http://www.lerf.eco.br/img/publicacoes/Emerging\%20Threats\%20and\%20Opportunities\%20for\%20LargeScale\%20Ecological\%20Restoration\%20in\%20the\%20Atlantic\%20Forest\%20of\%20Brazil.pdf $>$. Acesso em: 20/06/2016. <doi:10.1111/j.1526-100X.2011.00772.x>

FONSECA, J. R. H. O ministério público e a ação civil pública na defesa das áreas de preservação permanente e de RL. Hiléia, Hiléia (UEA), v. 9, p. 83-100, 2013.

KENGEN, S. A política florestal brasileira: uma perspectiva histórica. I SIAGEF, 2001. In: Trabalhos Convidados - IPEF. Porto Seguro, BA.

NUNES, E. J. S. Análise histórica da legislação brasileira - exame da constitucionalidade do art. 68 da lei 12.651/2012 e remédio jurídico para questioná-lo - ônus da prova de demonstrar a supressão da vegetação. 2014.

FLORESTA, Curitiba, PR, v. 48, n. 1, p. 27-36, jan. /mar. 2018.

Oliveira. A.L. et al.

ISSN eletrônico 1982-4688

DOI: $10.5380 /$ rf.v48 i 1.49110 
138f. Dissertação (Mestrado em Ciências) - Universidade de São Paulo, Escola Superior de Agricultura "Luiz de Queirós", Piracicaba, SP.

SANTiAgO, A. F. Reserva Legal. Revista de Direito Agrário, Brasília, n. 18, p. 45-63, 2006. Disponível em: <http://www.mda.gov.br/sitemda/sites/sitemda/files/user_arquivos_64/pageflip-4001789-74145-

lt_Revista_de_Direito_Ag-4802435.pdf>. Acesso em: 10/03/2016.

SANTIAGO, T. M. O.; REZENDE, J. L. P.; BORGES, L. A. C. The legal reserve: historical basis for the understanding and analysis of this instrument. Ciência Rural, v. 47, n. 2, 2017. Disponível em: < http://www.scielo.br/pdf/cr/v47n2/1678-4596-cr-47-02-20141349.pdf>. Acesso em: 22/11/2017. http://dx.doi.org/10.1590/0103-8478cr20141349.

SILVA, J. B. A. Lembranças e Apontamentos do Governo Provisório para os Senhores Deputados da Província de São Paulo. José Bonifácio Obra Completa. Disponível em: <http://www.obrabonifacio.com.br/colecao/obra/1266/digitalizacao/pagina/7>. Acesso em: 20/10/2014.

SILVA, J. S.; RANIERI, V. E. L. O mecanismo de compensação de RL e suas implicações econômicas e ambientais. Ambient. Soc., São Paulo, v.17, n.1, p.115-132, mar. 2014. Disponível em: <http://www.scielo.br/pdf/asoc/v17n1/v17n1a08.pdf>. Acesso em: 25/03/2016.

SOARES-FILHO, B.; B., RAJÃO, R.; MACEDO, M.; CARNEIRO, A.; COSTA, W.; COE, M.; RODRIGUES, H.; ALENCAR, A. Cracking Brazil's forest code. Science, v. 344, n. 6182, p. 363-364, 2014. Disponível em: <http://science.sciencemag.org/content/344/6182/363>. Acesso em: 25/03/2016. 